\title{
Expression of CD74 in bladder cancer and its suppression in association with cancer proliferation, invasion and angiogenesis in HT-1376 cells
}

\author{
JUN-WEI GAI ${ }^{*}$, WASILIJIANG WAHAFU ${ }^{2 *}$, LIMING SONG $^{2}$, HAO PING $^{2}$, MINGSHUAI WANG ${ }^{2}$, \\ FEIYA YANG ${ }^{2}$, YINONG NIU ${ }^{2}$, WEI QING ${ }^{3}$ and NIANZENG XING ${ }^{2}$ \\ ${ }^{1}$ Department of Urology, Tianjin First Central Hospital, Tianjin 300191; ${ }^{2}$ Department of Urology, Beijing Chao-Yang Hospital, \\ Beijing 100020; ${ }^{3}$ Department of Orthopedics, Xiangyang Central Hospital, Xiangyang, Hubei 441021, P.R. China
}

Received February 5, 2017; Accepted February 7, 2018

DOI: $10.3892 / \mathrm{ol} .2018 .8309$

\begin{abstract}
The aim of the present study was to investigate the expression and potential roles of CD74 in human urothelial cell carcinoma of the bladder (UCB) in vitro and in vivo. CD74 and macrophage migration inhibitory factor (MIF) were located and assayed in normal and UCB samples and cell lines using immunostaining. CD74 was knocked down using CD74 shRNA lentiviral particles in HT-1376 cells. The proliferative, invasive potential and microvessel density (MVD) of knockdown-CD74 HT-1376 cells were analyzed in vitro or in vivo. The expression of $\mathrm{CD} 74$ in an additional high grade UCB J82 cell line was also verified in vivo. All experiments were repeated at least 3 times. The majority of muscle-invasive bladder cancer (MIBC) samples, and only one high grade UCB cell line, HT-1376, expressed CD74, compared with normal, non- muscle-invasive bladder cancer (NMIBC) samples and other cell lines. The levels of proliferation and invasion were decreased in the CD74 knockdown-HT-1376 cells, and western
\end{abstract}

Correspondence to: Professor Wei Qing, Department of Orthopedics, Xiangyang Central Hospital, 39 Jingzhou Street, Xiangcheng, Xiangyang, Hubei 441021, P.R. China

E-mail: uro_dr@163.com

Professor Nianzeng Xin, Department of Urology, Beijing Chao-Yang Hospital, 8 Gongren Tiyuchang Nanlu, Beijing 100020, P.R. China

E-mail: nianzengxing@yeah.net

*Contributed equally

Abbreviations: UCB, urothelial cell carcinoma of the bladder; NMIBC, non-muscle-invasive bladder cancer; MIBC, muscle-invasive bladder cancer; MIF, macrophage migration inhibitory factor; VEGF, vascular endothelial growth factor; MMP, matrix metalloproteinase; NF- $\kappa \mathrm{B}$, Nuclear Factor $\kappa \mathrm{B}$; PCNA, Proliferating Cell Nuclear Antigen; Erk1/2, Extracellular regulated protein kinase 1/2; TLR4, Toll-like receptor 4; Dox, doxorubicin

Key words: cluster of differentiation 74, bladder cancer, proliferation, invasion, angiogenesis blotting assay indicated that the levels of proteins associated with proliferation, apoptosis and invasion in the cells were affected correspondingly by different treatments in vitro. The tumorigenesis and MVD assays indicated less proliferation and angiogenesis in the knockdown-HT-1376 cells compared with the scramble cells. Notably, J82 cells exhibiting no signal of CD74 in vitro presented the expression of CD74 in vivo. The present study revealed the potential roles of CD74 in the proliferation, invasion and angiogenesis of MIBC, and that it may serve as a potential therapeutic target for UCB, but additional studies are required.

\section{Introduction}

Urothelial cell carcinoma of the bladder (UCB) is a common urogenital malignancy worldwide, and in the United States of America $\sim 17,000$ patients succumb to UCB annually (1). There are 2 distinct complex pathways that occur in the initiation/progression of UCB (2), and the present study aimed to identify specific molecular marks or targets for UCB, particularly low aggressive non-muscle-invasive bladder cancer (NMIBC) and the highly aggressive muscle-invasive bladder cancer $(\mathrm{MIBC})(1,3,4)$. Assessment of the risks of recurrence and progression to MIBC remains a major problem for urologists (5).

Meyer-Siegler et al (6), demonstrated that the inhibition of macrophage migration inhibitory factor (MIF) may decrease UCB cells proliferation and cytokine expression through the MIF-cluster of differentiation (CD)74 pathway. Taylor et al (7), suggested that MIF may serve a role in the progression to invasive bladder cancer. However, growing evidence has suggested that MIF-targeted therapy may be potentially hazardous to health, considering that MIF participates in various host defense and immunological reactions to inflammation (8-11). Conversely, CD74 has indicated limited expression in normal human tissues, and was suggested to be the integrant chaperone for MIF receptors including CD44, C-X-C chemokine receptor (CXCR)2, CXCR4 or Toll-like receptor 4 (TLR4), to compose receptor complexes, modulate cell proliferation/apoptosis, initiate signal transduction of the Nuclear Factor $\kappa \mathrm{B}(\mathrm{NF}-\kappa \mathrm{B})$, Extracellular regulated protein kinase 1/2 (Erk1/2) and the 
Phosphoinositide 3'-kinase/RAC-alpha serine/threonine protein kinase (PI3K/Akt) pathway, and in turn participate in a number of processes including inflammation and carcinogenesis (12-16). At present, CD74 expression was demonstrated to be increased only in high-grade UCB (16). In light of these data, experiments investigating the effect of CD74-knockdown on UCB cells may be a promising strategy for treatment.

In the present study, the potential association between the expression levels of MIF and CD74 with clinical and pathological characteristics were analyzed, and whether the knockdown of CD74 would affect protein expression, proliferation, apoptosis, invasion, angiogenesis and signal transduction associated with UCB was also explored.

\section{Materials and methods}

Samples, cell lines and agents. Human tissue specimens were obtained from 108 patients with UCB (mean age, $63.4 \pm 11.3$ years, age range 45-74 years) who underwent either transurethral resection or radical cystectomy, and 20 patients who had received either cystoscopic biopsy, ureteral re-implantation or cystoprostatectomy (mean age, 62.8 \pm 13.0 years, age range 41-82 years) in Beijing Chao-Yang Hospital (Beijing, China) from August 2004 to March 2013. Informed consent was obtained from all patients enrolled. Tumors staged as carcinoma in situ were not included. The present study was approved by the Beijing Chao-Yang Hospital Institutional Research Ethical Board. All samples were confirmed and staged according to the American Joint Committee on Cancer TNM standard, and graded by 2 independent experienced genitourinary pathologists of the Beijing Chao-Yang Hospital (Beijing, China) (17). Table I summarizes the clinical and pathological characteristics of all patients enrolled.

The human immortalized urothelial cell line SV-HUC-1, and UCB SW780 (G1 stage), 5637 (G2), T24 (G3), J82 (G3) and HT-1376 (G3) cell lines were purchased from the Type Culture Collection of Chinese Academy of Sciences (Shanghai, China). SV-HUC-1 was cultured in F-12K medium (Hyclone; GE Healthcare Life Sciences, Logan, UT, USA). SW780 cells were cultured in Leibovitz's L-15 Medium (Hyclone; GE Healthcare Life Sciences), 5637, T24, J82 and HT-1376 were all cultured in RPMI-1640 (Hyclone; GE Healthcare Life Sciences) medium supplemented with $10 \%$ fetal bovine serum (Gibco; Thermo Fisher Scientific, Inc., Waltham, MA, USA). All cells were routinely cultured in a $37^{\circ} \mathrm{C}$ humidified incubator with $5 \% \mathrm{CO}_{2}$ and $95 \% \mathrm{O}_{2}$.

PBS, 3'-diaminobenzidine (DAB), EDTA and DAPI were obtained from Sigma-Aldrich; Merck KGaA (Darmstadt, Germany). Commercial CD74 short hairpin (sh)RNA lentiviral particles (cat. no., sc-35023-v), scramble shRNA lentiviral particles (cat. no., sc-108080) and CD34 (cat. no., sc-65261; dilution, 1:400) and NF- $\mathrm{B}$ p65 antibodies (cat. no., sc-71677; dilution, 1:200) were purchased from Santa Cruz Biotechnology, Inc., (Dallas, TX, USA). The ELISA kits for vascular endothelial growth factor (VEGF; cat. no., 03-0068-00), matrix metalloproteinase (MMP)-2 (cat. no., MAB13431) and MMP-9 (cat. no., QIA56) were purchased from Calbiochem; EMD Millipore (Billerica, MA, USA). Cyclin D1 (cat. no., 2922S; dilution, 1:800), Cyclin B1 (cat. no., 4138S; dilution, 1:500), Proliferating Cell Nuclear
Antigen (cat. no., 13110S; dilution, 1:800), B-cell lymphoma 2 (Bcl-2; cat. no., 3498S; dilution, 1:500), Bcl-extra large (Bcl-xL; cat. no., 2762S; dilution, 1:500), Bcl-2-associated X protein (Bax; cat. no., 2774S; dilution, 1:800), Bcl-2-associated death protein (Bad; cat. no., 9292S; dilution, 1:500) and GAPDH (cat. no., 8884S; dilution, 1:1,000) antibodies were sourced from Cell Signaling Technology (CST, Boston, MA). Erk1/2 (cat. no., V114A; dilution, 1:2,000), phosphorylated Erk1/2 (pErk1/2; cat. no., 9101S; dilution, 1:500), cleaved poly (adenosine 5'-diphosphate-ribose) polymerase (PARP) p85 (cat. no., G734A; dilution, 1:300) antibodies were purchased from Promega Corporation (Madison, WI, USA).

ELISA of VEGF, MMP-2 and MMP-9. Following $48 \mathrm{~h}$ of incubation, the HT-1376 cells culture media of the basal chamber of control and CD74-shRNA were collected separately. Following centrifugation $\left(12,000 \mathrm{x} g\right.$ at $4^{\circ} \mathrm{C}$ for $\left.15 \mathrm{~min}\right)$, the protein levels were measured prior to ELISA assay. The concentrations of the VEGF, MMP-2 and MMP-9 cytokines were determined by the corresponding ELISA kits according to the manufacturer's protocol; the absorbance was measured at 450 and $595 \mathrm{~nm}$ using a microplate reader (Bio-Rad Laboratories, Inc., Hercules, CA, USA).

Immunostaining image assay of MIF and CD74. Bladder tissue samples were examined by immunohistochemistry and immunofluorescence for the expression of MIF and CD74. Paraffin-embedded tissue sections (4- $\mu \mathrm{m}$ thick) were then dewaxed at room temperature for $5 \mathrm{~min}$ in $99.0 \%$ xylene and rehydrated in graded ethanol solutions (two washes of $100 \%$ ethanol for $10 \mathrm{~min}$ each and two washes of $95 \%$ ethanol for 10 min each). Antigen retrieval was performed following standard procedures: Sections were cooled and immersed in 3\% hydrogen peroxide solution for $15 \mathrm{~min}$ to block endogenous peroxidase activity at room temperature, and rinsed in PBS for $5 \mathrm{~min}$. Non-specific labeling was blocked by incubation with $5 \%$ bovine serum albumin (Thermo Fisher Scientific, Inc., Waltham, MA, USA) at room temperature for $30 \mathrm{~min}$. Sections were then incubated with primary antibodies against MIF (cat. no., sc-271631; dilution, 1:200) or CD74 (cat. no., sc-70781; 1:200; Santa Cruz Biotechnology, Inc.) at $4^{\circ} \mathrm{C}$ overnight. They were then rinsed with PBST three times, and incubated at $37^{\circ} \mathrm{C}$ for $15 \mathrm{~min}$ with horseradish peroxidase (HRP)-conjugated goat $\mathrm{IgG}$ secondary antibody (cat. no., sc-2354; dilution, 1:50; Santa Cruz Biotechnology, Inc.), developed with HRP-conjugated streptavidin and DAB (2.5 $\mathrm{ml}$ 10X DAB solution and $22.5 \mathrm{ml}$ of stable peroxide substrate buffer; Sigma-Aldrich; Merck KGaA) for $1 \mathrm{~h}$ at room temperature and counterstained with hematoxylin for $2 \mathrm{~min}$. The immunohistochemical results were then scored by two independent pathologists of Beijing Chao-Yang Hospital (Beijing, China). Staining intensity (percentage of positively tumor cells among all tumor cells) was scored as '-' (negative), ' + ' (moderate) or ' ++ ' (strong). The extent of staining was scored as '-' (<20\% of urothelial cells stained), '+' (20-60\% stained) or ' ++ ' ( $>60 \%$ stained).

UCB cell-covered slides were collected from the media and washed twice using PBS, and then sections were incubated for $60 \mathrm{~min}$ at $37^{\circ} \mathrm{C}$ with fluorescein isothiocyanate- anti-mouse secondary antibody (Santa Cruz Biotechnology, Inc.). Finally, 
Table I. Association between MIF and CD74 expression with clinical and pathological characteristics of patient samples.

\begin{tabular}{|c|c|c|c|c|c|c|c|c|c|}
\hline \multirow[b]{2}{*}{ Characteristics } & \multirow[b]{2}{*}{ Total } & \multicolumn{3}{|c|}{ MIF } & \multirow[b]{2}{*}{ P-value } & \multicolumn{3}{|c|}{ CD74 } & \multirow[b]{2}{*}{ P-value } \\
\hline & & - & + & ++ & & - & + & ++ & \\
\hline \multicolumn{10}{|l|}{ Sex } \\
\hline Male & 92 & - & - & - & - & - & - & - & - \\
\hline Female & 36 & - & - & - & - & - & - & - & - \\
\hline Age, mean $\pm \mathrm{SD}$ & $62.9 \pm 11.6$ & & & & & & & & \\
\hline Normal patients (20) & $62.8 \pm 13.0$ & 5 & 7 & 8 & & 9 & 10 & 1 & - \\
\hline UCB patients (108) & $63.4 \pm 11.3$ & 12 & 28 & 30 & & 25 & 26 & 19 & - \\
\hline \multicolumn{10}{|l|}{ UCB Pathology } \\
\hline Stage & & & & & 0.106 & & & & $<0.001$ \\
\hline NMIBC (pTa, pT1) & 70 & 12 & 28 & 30 & & 25 & 26 & 19 & \\
\hline MIBC (pT2-T4) & 38 & 3 & 12 & 23 & & 4 & 8 & 26 & \\
\hline Grade & & & & & 0.631 & & & & $<0.001$ \\
\hline Low & 36 & 8 & 10 & 18 & & 20 & 12 & 4 & \\
\hline High & 72 & 7 & 30 & 35 & & 10 & 22 & 40 & \\
\hline Lymphogenous metastasis & & & & & 0.148 & & & & 0.031 \\
\hline- & 94 & 13 & 38 & 43 & & 29 & 30 & 35 & \\
\hline+ & 14 & 2 & 2 & 10 & & 1 & 4 & 9 & \\
\hline
\end{tabular}

MIF, macrophage migration inhibitory factor; CD74, cluster of differentiation.

4',6-diamidino-2-phenylindole (Sigma-Aldrich; Merck KGaA) was used to treat the slides. Images were captured using a confocal-microscope in 3 fields of view (magnification, x100; Olympus, Tokyo, Japan).

Western blotting assay. Lysis buffer (Bio-Rad Laboratories, Inc.) was used to prepare the tissue and cells, and protein concentrations were measured by Bradford's method (18). A total of $50 \mu \mathrm{g}$ protein was placed in each lane of $12 \%$ SDS-PAGE (Bio-Rad Laboratories, Inc.), and then transferred onto nitrocellulose membranes (Bio-Rad Laboratories, Inc.). Fat-free milk powder (5\%) was used to block membranes, which was incubated in primary antibodies overnight at $4^{\circ} \mathrm{C}$, and then with HRP-conjugated secondary antibodies (Santa Cruz Biotechnology, Inc.). A electrochemiluminescent reagent (Pharmacia Corp., Basking Ridge, NJ, USA) was used to detect signals and the Kodak Image Station 4000MM Pro (Kodak, Rochester, NY, USA) was used for analyzing and recording.

Reverse transcription polymerase chain reaction (RT-PCR) assay. Total RNA of untreated, scramble shRNA and CD74-targeted shRNA transfected HT-1376 cells were extracted for the RT-PCR assay using an RNeasy kit (cat. no., 74104) (Qiagen Sciences, Inc., Gaithersburg, MD, USA) according to the manufacturer's protocol. The primers were as follows: CD74 Forward, 5'-CGGAAGATCAGA AGCCAGTC-3'; and CD74 reverse, 5'-GCGAGGAGCAGA GTCACCAG-3'; GAPDH forward, 5'-GTCAAGGCTGAG AACGGGAA-3'; and GAPDH reverse 5'-GCGAGGAGCAGA GTCACCAG-3'. A total of 35 cycles of PCR $\left(95^{\circ} \mathrm{C}\right.$ for $40 \mathrm{sec}$, $45^{\circ} \mathrm{C}$ for $40 \mathrm{sec}$, and $72^{\circ} \mathrm{C}$ for $60 \mathrm{sec}$ ) were completed for CD74 and GAPDH, and the expression of CD74 was normalized to that of GAPDH.

Transfection of lentivirus CD74 shRNA in HT-1376 cells. The CD74 shRNA lentiviral particles (cat. no., sc-35023-V; 1.0x10\%/200 $\mu$; Santa Cruz Biotechnology, Inc.) targeting the human CD74 transcript and control shRNA lentiviral particles (cat. no., sc-108080; 1.0x106/200 $\mu \mathrm{l}$; Santa Cruz Biotechnology, Inc.) were used to knock down CD74 in HT-1376 cells. Cells were seeded at $2 \times 10^{5}$ cells/well in 6-well plates (Corning Incorporated, Corning, NY, USA) and grown to $60 \%$ confluence on the day of transfection. The media was removed from the plate wells and replaced with $2 \mathrm{ml}$ complete medium containing Polybrene (cat. no., sc-134220; Santa Cruz Biotechnology, Inc.) at a final concentration of $5 \mu \mathrm{g} / \mathrm{ml}$. Cells were transfected with control (scramble, $20 \mu \mathrm{l}$ ) or CD74 shRNA lentiviral particles (20 $\mu \mathrm{l})$ diluted in media according to the manufacturer's protocol in $48 \mathrm{~h}$. Infected cells were selected with puromycin (5 $\mu \mathrm{g} / \mathrm{ml}$; cat. no., 11811-023; Gibco; Thermo Fisher Scientific, Inc., Waltham, MA, USA). A total of $72 \mathrm{~h}$ after transfection, transfected cells were verified by RT-PCR and western blotting analysis, comparing untreated and scramble cells.

Cell vitality assay. A cell vitality test was performed using the CellTiterTM 96 Aqueous assay kit (cat. no., G358C; Promega Corporation) and performed according to the instructions of the manufacturer. The HT-1376 cells (10,000/well) were seeded in 96-well plates (Corning Incorporated) and incubated at $37^{\circ} \mathrm{C}$, and transfected with control or CD74 shRNA lentiviral particles after $24 \mathrm{~h}$. Cell proliferation was assessed 
after transfected 2, 4, 6, 8 and 10 days, with control or CD74 shRNA lentiviral particles using a multiwall spectrophotometer (Bio-Rad Laboratories, Inc.).

Flow cytometry. Control or CD74-knockout HT-1376 cells were seeded in 6-well plates (Corning Incorporated) and incubated in medium without FBS at $37^{\circ} \mathrm{C}$ overnight. Then, the cells were rinsed 3 times and incubated in medium containing $10 \%$ FBS. The cells were collected and then fixed with $70 \%$ ethanol after $24 \mathrm{~h}$ at $4^{\circ} \mathrm{C}$. The cells were treated with $\geq 94.0 \%$ (HPLC) propidium iodide (Sigma-Aldrich; Merck KGaA) and RNase A $(400 \mathrm{U} / \mathrm{ml})$ for $30 \mathrm{~min}$ at $4^{\circ} \mathrm{C}$. Cellular content of DNA was evaluated by the flow cytometer (FACSCalibur; BD Biosciences, Erembodegem, Belgium), and cell cycle analysis was performed using ModFit2.0 software (BD Biosciences).

Cell invasion assay. A cell invasion assay was performed with 24-well Transwell inserts (Corning Incorporated). Following transfected with control or CD74 shRNA lentiviral particles, HT-1376 cells were starved in serum-free RPMI-1640 medium overnight, and $1 \times 10^{4}$ cells were re-suspended in $200 \mu \mathrm{l}$ serum-free RPMI-1640 medium and placed in the upper chambers with $8 \mu \mathrm{m}$ filter pores in triplicate. The membrane undersurface was coated with $30 \mu \mathrm{l} \mathrm{ECM} \mathrm{gel} \mathrm{from}$ Engelbreth-Holm-Swarm mouse sarcoma (BD Biosciences) mixed with FBS-free RPMI-1640 medium in 1:5 dilution for $30 \mathrm{~min}$ at $37^{\circ} \mathrm{C}$. The lower chamber was filled with $500 \mu 110 \%$ FBS as the chemoattractant and incubated for $48 \mathrm{~h}$ at $37^{\circ} \mathrm{C}$. Following this, the cells on the upper surface of the membrane were removed by cotton buds, and the cells on the lower surface of the insert were fixed in 4\% PBS-buffered paraformaldehyde for $5 \mathrm{~min}$ at room temperature and stained with $0.1 \%$ crystal violet (Sigma-Aldrich; Merck KGaA) for 5 min at room temperature. A total of 5 visual fields were chosen randomly for each insert and images were captured under a light microscope (magnification, x100). The cells were counted and the data were presented as mean \pm standard deviation (SD) and presented by a percentage of controls.

Tumorigenesis assay. Cells ( $1 \times 10^{7}$ cells/mouse) were injected subcutaneously into the axilla area of 6-week-old male BALB/c-nu mice (20/group,total 40 mice), which were purchased from the Experimental Animal Center of Peking University Health Science, and animals remained in a pathogen-free animal facility. Mice had access to food and water ad libitum, and were kept at a temperature of $20 \sim 26^{\circ} \mathrm{C}$, a humidity of $30-70 \%$ and in a $12 \mathrm{~h}$ light $/ 12 \mathrm{~h}$ dark cycle). The CD74 scramble shRNA and knockdown-HT-1376 cells, and untreated J82 cells were all included in the analysis. Tumor diameter was measured every 7 days, and tumor sizes were measured following sacrifice via cervical dislocation at 28 days, using the following formula: Length $\mathrm{x}$ width ${ }^{2} \mathrm{x} 0.5$. All tumor ulceration observed was monitored by the laboratory staff. All experiments in the present study were performed in strict accordance with the recommendations in the Association for Assessment and Accreditation to Laboratory Animal Care International (19).

Microvessel density (MVD). Anti-CD34 antibody (Abcam, Cambridge, MA)-stained slides were examined with a light microscope. Cells positive for CD34 were designated as a vessel (20) and observed at magnification, x100 to select high areas of MVD. Then, the MVD of CD34-positive cells was investigated at magnification, $\mathrm{x} 200$.

Statistical analysis. Values were represented as mean \pm standard deviation and analyzed with SPSS v15.0 (SPSS, Inc., Chicago, IL, USA). The $\chi^{2}$ test and Mann-Whitney U test were used to analyze the data in Table I, and Dunnett test was used to analyze cell proliferation and xenograft tumor volume data. $\mathrm{P}<0.05$ was considered to indicate a statistically significant difference. Each experiment was repeated 3 times.

\section{Results}

MIBC samples and HT-1376 cells exhibit higher levels of CD74 compared with normal tissues and UCB cells. Table I summarizes and analyzes the association between the clinical characteristics and histological results of all UCB cases enrolled. The immunohistochemical assay indicated that only CD74 expression was statistically significant in MIBC, high grade and lymph node metastasis specimens $(\mathrm{P}<0.001$, $\mathrm{P}<0.001$ and $\mathrm{P}=0.031$, respectively), while no different between normal patients and NMIBC patients $(\mathrm{P}=0.126)$. At the same time, there were no statistically significant between normal patients and NMIBC $(\mathrm{P}=0.615)$, and between normal patients and MIBC patients $(\mathrm{P}=0.061)$ in MIF expression. All samples exhibited marked MIF signals, and only MIBC samples revealed CD74 signals (Fig. 1A). Western blotting demonstrated that only the HT-1376 cells presented CD74, and that all cells expressed MIF (Fig. 1B and C).

Expression levels of proteins associated with proliferation, invasion and angiogenesis are affected by knockdown of CD74 in HT-1376 cells. RT-PCR and Western blot analysis showed that CD74 shRNA lentiviral particles were reduced CD74 expression in HT-1376 cells (Fig. 1D and E). Western blotting assays indicated that Cyclin D1, Cyclin E (Fig. 1F), Bcl-xL (Fig. 1G), pErk1/2, pAkt, Akt and intranuclear NF-кB (Fig. 1H) levels in the CD74-knockdown HT-1376 cells were downregulated compared with untreated cells.

Knockdown of CD74 by CD74 shRNA lentiviral particles suppresses the proliferative and invasive abilities of HT-1376 cells. Knockdown of CD74 attenuated cell proliferation in HT-1376 cells compared with the scramble group (Fig. 2A). The flow cytometry assay indicated that knockdown of CD74 significantly increased the proportion of G1-stage cells $(\mathrm{P}<0.001)$ and decreased the proportions of $\mathrm{G} 2$ stage $(\mathrm{P}<0.001)$ and $\mathrm{S}$ stage cells $(\mathrm{P}=0.0149)$, compared with scramble shRNA cells (Fig. 2B). The cell invasion assay showed that knockdown of CD74 significantly attenuated the invasion ability of HT-1376 cells (Fig. 2C and D). An indicated that the secretion of VEGF and MMP-9 was significantly reduced in CD74-knockdown-HT-1376 cells compared with the shRNA control, while not significantly reduced in MMP-2 (Fig. 2E and F).

CD74 knockdown inhibits UCB growth and MVD in xenograft nude mice. CD74 knockdown inhibited the tumorigenesis of HT-1376 cells in vivo (Fig. 3A-C). The average weight 
A

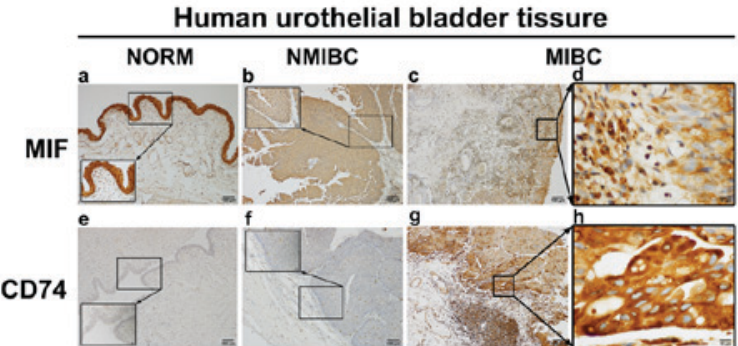

B

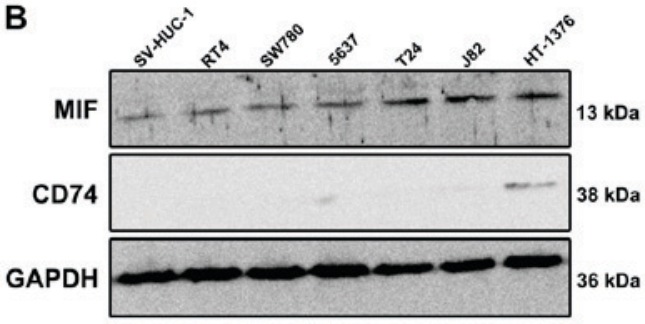

C

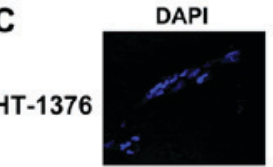

D

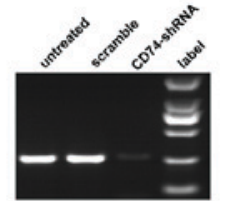

CD74

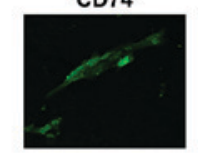

E

CD74

GAPDH
Merged

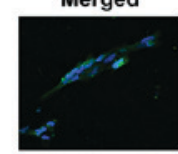

F
Cyclin D
Cyclin E

PCNA

Cyclin A

Cyclin B

GAPDH
G
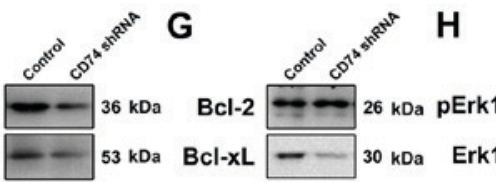

H

Bcl-2

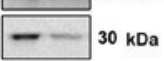

Erk1/2

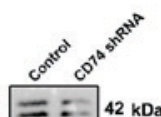

三 : $42 \mathrm{kDa}$

- $36 \mathrm{kDa}$

- $54 \mathrm{kDa}$

Bax

$-23 \mathrm{kDa}$

pakt

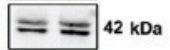

Bad

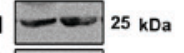

Akt

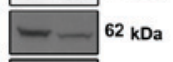

$-$

$37 \mathrm{kDa}$ GAPDH

$-\infty 5 \mathrm{kDa}$ NF-KB*
$-37 \mathrm{kDa}$ GAPDH

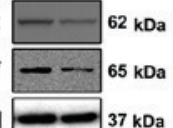

Figure 1. Expression of MIF and CD74 in tissue samples and cells, and protein expression levels in HT-1376 cells following knockdown of CD74. (A) Little or no expression of immunoreactive CD74 was identified in the urothelial layers of normal bladder and NMIBC samples, but sections of MIBC samples exhibited strong immunoreactive signals of CD74. In contrast, MIF demonstrated strong immunoreactions in the normal and UCB samples. (B) Western blotting assay results for MIF and CD74 in the cultured urothelial SV-HUV-1, SW780, 5637, T24, J82 and HT-1376 cell lines. HT-1376 was the only one identified to express CD74, but all cells expressed MIF to a certain extent. (C) Immunofluorescence microscopy (x100, magnification) indicated positive CD74 staining in HT-1376 cells. (D) CD74 shRNA lentiviral particles abrogated the RNA expression of CD74 in the HT-1376 cells compared with untreated and scramble cells. (E) CD74 short hairpin RNA lentiviral particles abrogated the protein expression of CD74 in the HT-1376 cells when compared with the untreated and scramble cells. (F) Knockdown of CD74 modulated the expression levels of not only Cyclin D1, Cyclin E, but also intranuclear NF-kB p65, pAkt, pErk1/2. (G and H) However, no significant changes in Bcl-2, Bad, cleaved PARP and Erk1/2 were observed among all groups. *intranuclear NF-kB. NMIBC, non-muscle-invasive bladder cancer; MIBC, muscle-invasive bladder cancer; UCB, urothelial cell carcinoma of the bladder; MIF, macrophage migration inhibitory factor; CD74, cluster of differentiation; p65, transcription factor p65; Akt, RAC-alpha serine/threonine protein kinase; p, phosphorylated; Erk1/2, Extracellular regulated protein kinase 1/2; Bcl-2, B-cell lymphoma 2; Bcl-xL, Bcl-extra large; Bax, Bcl-2-associated X protein; PARP, poly(adenosine 5'-diphosphate-ribose) polymerase.

A
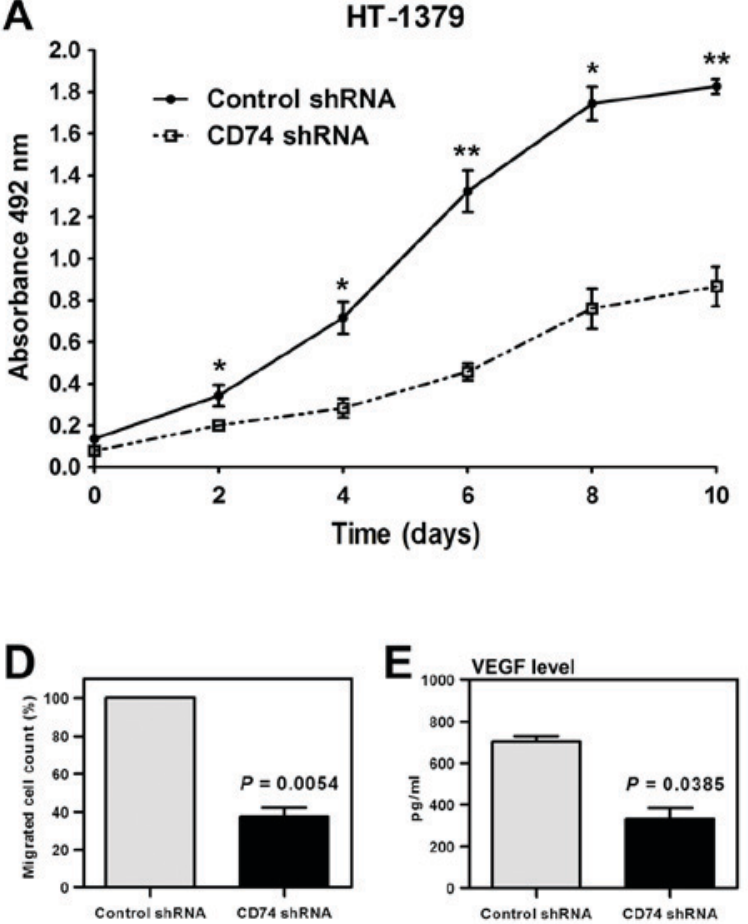

B

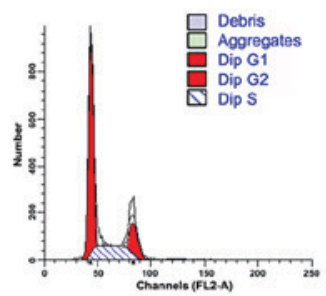

C

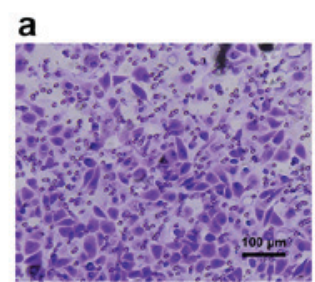

Control shRNA

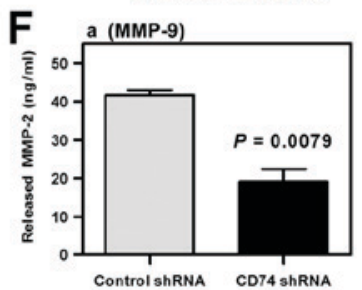

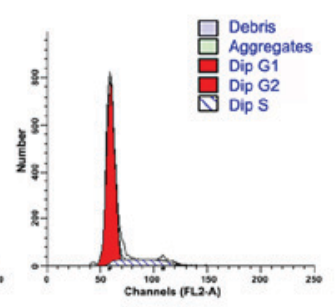

b

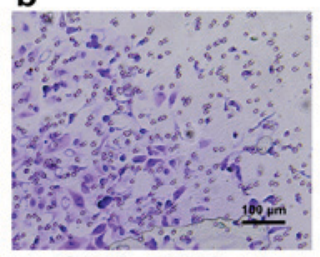

CD74 ShRNA

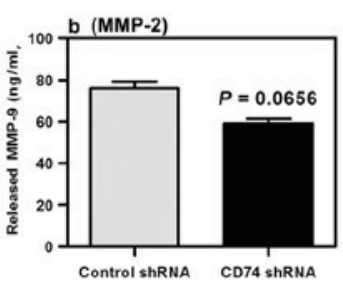

Figure 2. In vitro analysis of the effects of CD74-knockdown cells. (A) Knockdown of CD74 attenuated cell proliferation in HT-1376 cells compared with the scramble group. " $\mathrm{P}<0.05$ and ${ }^{* *} \mathrm{P}<0.01$ vs. Control shRNA. (B) Flow cytometry indicated that knockdown of CD74 significantly increased the proportion of G1 stage cells, decrease G2 stage and S stage ones, compared with scramble shRNA cells. (C) The cell invasion assay demonstrated that knockdown of CD74 significantly attenuated the invasion ability of HT-1376 cells, (D) and the cells of two groups were counted (mean \pm SD) and the data of CD74 shRNA group were presented by a percentage of control shRNA group. (E and F) ELISA test indicated that the secretion of (E) VEGF and MMP-9 (F-a) was significantly reduced in CD74-knockdown-HT-1376 cells compared to the shRNA control, while not significantly reduced in MMP-2 (F-b). CD74, cluster of differentiation; VEGF, vascular endothelial growth factor; MMP, matrix metalloproteinase; sh, short hairpin. 
A
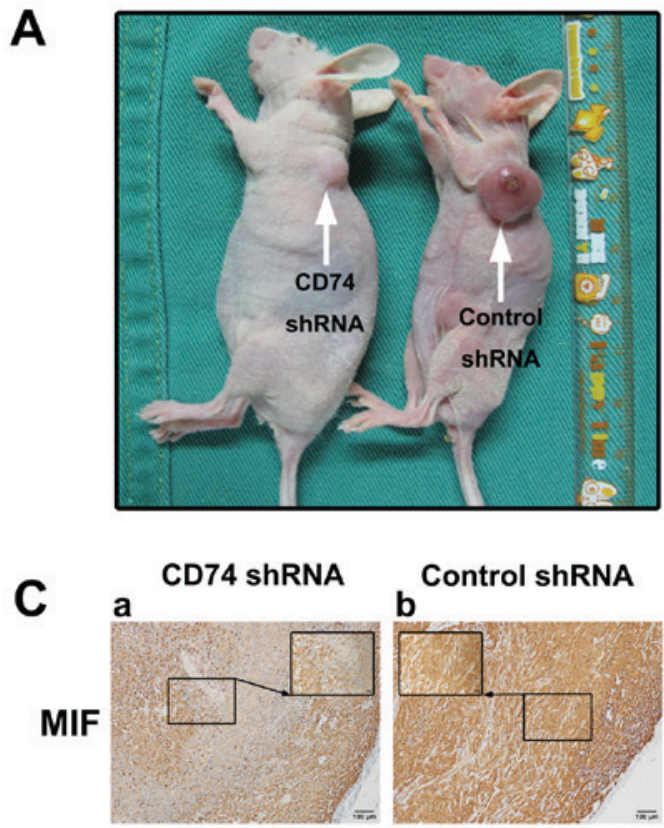

c

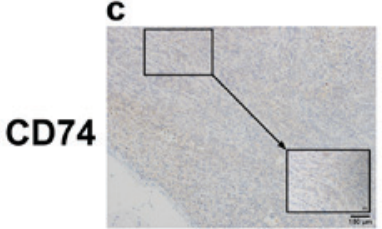

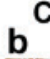

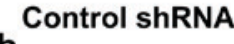

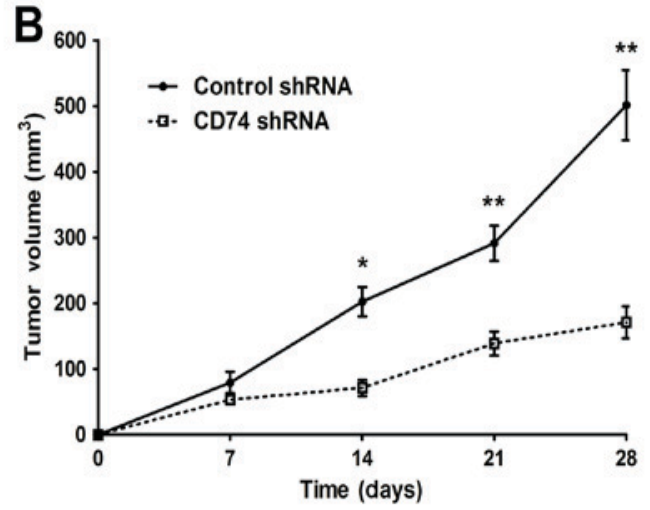

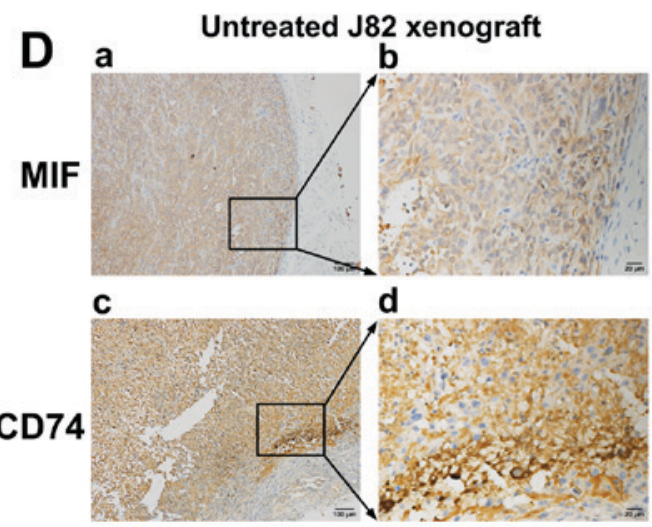

Figure 3. In vivo analysis of the effects of CD74-knockdown cells. (A) Volume of tumors derived from CD74-knockdown cells was significantly decreased compared with those derived from control cells in vivo. (B) The average weight of the tumors was significantly decreased in in the CD74 shRNA group. (C) Untreated HT-1376 xenograft tumors exhibited strong CD74 signals by immunochemistry. (D) CD74 in the wild-type J82 tumor was indicated using immunostaining. ${ }^{*} \mathrm{P}<0.05$ and ${ }^{* *} \mathrm{P}<0.01$ vs. Control shRNA. Magnification, $\mathrm{x} 100$.

of the tumors in the CD74 shRNA group was $24.20 \pm 2.19 \mathrm{~g}$ $(\% \Delta=6.92)$, and the average weight of the tumors in the control shRNA group was $22.37 \pm 0.98 \mathrm{~g}(\% \Delta=-2.32)$. The MVD values of $56.8 \pm 18.2$ and $42.9 \pm 14.7$ for scramble and CD74-knockdown groups, respectively, were significantly different $(\mathrm{P}=0.0114)$. CD74 in the wild-type J82 tumor was indicated using immunostaining (Fig. 3D).

\section{Discussion}

The present study investigated MIF and CD74 expression patterns in human normal and UCB samples and different cell lines, and also explored the association between the clinical characteristics and expression levels of MIF and CD74 in UCB cases, and the roles of CD74 in urothelial cells. The results suggested that MIF ubiquitously appeared in benign and malignant bladder tissues, but CD74 was expressed primarily in malignant UCB samples of MIBC, but also marginally in normal and NMIBC tissues, which suggests that CD74 may be a unique and promising marker for high-grade UCB or MIBC. In addition, knockdown of CD74 in the HT-1376 cells attenuated the level of proliferation, invasion and angiogenesis via downregulated Erk1/2 and PI3K/Akt pathways in the in vitro study, which was concordant with previous studies $(15,16)$. The tumorigenesis assay indicated that the knockdown of CD74 in the HT-1376 cells resulted in lower tumor volumes, and notably induced the expression of CD74 in the wild-type J82 tumors.
At first, CD74 was identified as a part of the major histocompatibility complex II and a chaperone of MIF, which was demonstrated to exert MIF functions within the immune system and initiate inflammation (21-23). CD74 is an evolutionarily-conserved type II protein expressed in the cellular membrane, and has various roles in several key processes including antigen presentation, B-cell differentiation, inflammatory signaling and carcinogenesis signaling $(14,15)$. Previous evidence has suggested that unlike MIF, which was ubiquitous in human tissue, CD74 was expressed in higher quantities in malignant tissues compared with benign tissues, and is an essential part of the MIF pathway axis (24-27).

In the present study, it was identified that the knockdown of CD74 decreased the level of proliferation, invasion (MMPs) and angiogenesis (VEGF and MVD) in UCB cells in the in vitro and in vivo experiments, which may be the result of the inhibition of Erk1/2 and PI3K/Akt pathways (28). MMPs are a family of proteolytic enzymes involved in a number of phases of cancer progression, including angiogenesis, invasiveness and metastasis, and may be downregulated by ISO-1, a specific inhibitor of MIF (29,30). VEGF and intranuclear NF- $\kappa \mathrm{B}$ also appear to be involved in the MIF-CD74 pathway $(31,32)$, which was also demonstrated in the present study.

The characteristics of CD74 have been investigated in a number of types of hematopoietic cancer for a long time $(13,33)$. The humanized mAb milatuzumab that targets CD74 has been 
assessed in clinical trials (34), and additional studies indicated that milatuzumab may conjugate with doxorubicin (Dox) and enhance the cytotoxicity of Dox $(34,35)$. Notably, Dox is an important agent in UCB intravesical chemotherapy, suggesting that CD74-targeted therapeutic treatment may be a better choice than DOX.

The present study has also demonstrated that UCB J82 cells exhibited no CD74 signals in vitro, but that they were induced to express CD74 in BALB/c-nu mice in vivo. Due to the number factors involved in the occurrence of tumor xenografts, we hypothesized that the pattern of chemokine-receptors expressed on cultured cells in vitro or individual cells in vivo was determined by the cell's lineage, state of differentiation, and micro-environmental factors including chemokines concentration, the presence of inflammatory cytokines and hypoxia (31). Additional studies in this area are required.

In the present study, the expression and potential roles of CD74 were analyzed via in vitro and in vivo experiments. It was indicated that the expression of CD74 was associated with MIBC/high grade of the UCB, while the knockdown of CD74 attenuated the proliferation, invasion and angiogenesis of HT-1376.

\section{Acknowledgements}

Not applicable.

\section{Funding}

This work was supported by the National Natural Science Foundation of China (grant no. 81302231), the Beijing Outstanding Talent Training (grant no.2014000021469G0104), the Beijing Municipal Administration of Hospitals' Youth Program (grant no. QML20160303) and the Beijing Chao-Yang Hospital 1351 Talents Project Funding (grant no. CYXX-201711).

\section{Availability of data and materials}

The datasets generated or analyzed during this study are included in this published article.

\section{Authors' contributions}

WQ and NX were responsible for the data analysis. JG and WW were major contributors in writing the manuscript and statistical analysis. LS, HP, and YN were responsible for the acquisition of data. MW and FY performed analysis and interpretation of data. All authors read and approved the final manuscript.

\section{Ethics approval and consent to participate}

Ethical approval was granted by the Beijing Chao-Yang Hospital Institutional Research Ethical Board. Informed consent was obtained from all patients enrolled.

\section{Consent for publication}

Informed consent was obtained from all patients enrolled.

\section{Competing interests}

The all authors declare that they have no competing interests.

\section{References}

1. Burger M, Catto JW, Dalbagni G, Grossman HB, Herr H, Karakiewicz P, Kassouf W, Kiemeney LA, La Vecchia C, Shariat S and Lotan Y: Epidemiology and risk factors of urothelial bladder cancer. Eur Urol 63: 234-241, 2013.

2. McConkey DJ, Lee S, Choi W, Tran M, Majewski T, Lee S, Siefker-Radtke A, Dinney C and Czerniak B: Molecular genetics of bladder cancer: Emerging mechanisms of tumor initiation and progression. Urol Oncol 28: 429-440, 2010.

3. Kaufman DS, Shipley WU and Feldman AS: Bladder cancer. Lancet 374: 239-249, 2009.

4. Serrano C, Morales R, Suárez C, Núñez I, Valverde C, Rodón J, Humbert J, Padrós O and Carles J: Emerging therapies for urothelial cancer. Cancer Treat Rev 38: 311-317, 2012.

5. Meeks JJ, Bellmunt J, Bochner BH, Clarke NW, Daneshmand S, Galsky MD, Hahn NM, Lerner SP, Mason M, Powles T, et al: A systematic review of neoadjuvant and adjuvant chemotherapy for muscle-invasive bladder cancer. Eur Urol 62: 523-533, 2012.

6. Meyer-Siegler KL, Leifheit EC and Vera PL: Inhibition of macrophage migration inhibitory factor decreases proliferation and cytokine expression in bladder cancer cells. BMC Cancer 4: 34, 2004.

7. Taylor JA III, Kuchel GA, Hegde P, Voznesensky OS, Claffey K, Tsimikas J, Leng L, Bucala R and Pilbeam C: Null mutation for macrophage migration inhibitory factor (MIF) is associated with less aggressive bladder cancer in mice. BMC Cancer 7: 135, 2007.

8. Al-Abed Y and VanPatten S: MIF as a disease target: ISO-1 as a proof-of-concept therapeutic. Future Med Chem 3: 45-63, 2011.

9. Babu SN, Chetal G and Kumar S: Macrophage migration inhibitory factor: A potential marker for cancer diagnosis and therapy. Asian Pac J Cancer Prev 13: 1737-1744, 2012.

10. Calandra $\mathrm{T}$ and Roger T: Macrophage migration inhibitory factor: A regulator of innate immunity. Nat Rev Immunol 3: 791-800, 2003.

11. Larson DF and Horak K: Macrophage migration inhibitory factor: Controller of systemic inflammation. Crit Care 10: 138, 2006.

12. Becker-Herman S, Arie G, Medvedovsky H, Kerem A and Shachar I: CD74 is a member of the regulated intramembrane proteolysis-processed protein family. Mol Biol Cell 16: 5061-5069, 2005.

13. Borghese F and Clanchy FI: CD74: An emerging opportunity as a therapeutic target in cancer and autoimmune disease. Expert Opin Ther Targets 15: 237-251, 2011.

14. Lue H, Thiele M, Franz J, Dahl E, Speckgens S, Leng L, Fingerle-Rowson G, Bucala R, Lüscher B and Bernhagen J: Macrophage migration inhibitory factor (MIF) promotes cell survival by activation of the Akt pathway and role for CSN5/JAB1 in the control of autocrine MIF activity. Oncogene 2635: 5046-5059, 2007.

15. Starlets D, Gore Y, Binsky I, Haran M, Harpaz N, Shvidel L, Becker-Herman S, Berrebi A and Shachar I: Cell-surface CD74 initiates a signaling cascade leading to cell proliferation and survival. Blood 107: 4807-4816, 2006.

16. Choi JW, Kim Y, Lee JH and Kim YS: CD74 expression is increased in high-grade, invasive urothelial carcinoma of the bladder. Int J Urol 20: 251-255, 2013.

17. Edge S, Byrd D, Compton C, Fritz A, Greene F and Trotti A: AJCC cancer staging manual. edition 7. New York, NY: Springer, 2010.

18. Bradford MM: A rapid and sensitive method for the quantitation of microgram quantities of protein utilizing the principle of protein-dye binding. Anal Biochem 72: 248-254, 1976.

19. Association for assessment and accreditation of laboratory animal care international. [Internet]. 2011. AAALAC International rules of accreditation. Section 2.d. [Cited April 2012]. Available at: http://www.aaalac.org/accreditation/rules.cfm

20. Offersen BV, Pfeiffer P, Hamilton-Dutoit S and Overgaard J: Patterns of angiogenesis in nonsmall-cell lung carcinoma. Cancer 91: 1500-1509, 2001.

21. Cooke G, Armstrong ME and Donnelly SC: Macrophage migration inhibitory factor (MIF), enzymatic activity and the inflammatory response. Biofactors 35: 165-168, 2009.

22. Conroy H, Mawhinney L and Donnelly SC: Inflammation and cancer: Macrophage migration inhibitory factor (MIF)-the potential missing link. QJM 103: 831-836, 2010. 
23. Bernhagen J, Krohn R, Lue H, Gregory JL, Zernecke A, Koenen RR, Dewor M, Georgiev I, Schober A, Leng L, et al: MIF is a noncognate ligand of CXC chemokine receptors in inflammatory and atherogenic cell recruitment. Nat Med 13: 587-596, 2007.

24. Cheng RJ, Deng WG, Niu CB, Li YY and Fu Y: Expression of macrophage migration inhibitory factor and CD74 in cervical squamous cell carcinoma. Int J Gynecol Cancer 21: 1004-1012, 2011.

25. Zheng YX, Yang M, Rong TT, Yuan XL, Ma YH, Wang ZH, Shen LS and Cui L: CD74 and macrophage migration inhibitory factor as therapeutic targets in gastric cancer. World J Gastroenterol 18: 2253-2261, 2012.

26. Metodieva G, Nogueira-de-Souza NC, Greenwood C, Al-Janabi K, Leng L, Bucala R and Metodiev MV: CD74-dependent deregulation of the tumor suppressor scribble in human epithelial and breast cancer cells. Neoplasia 15: 660-668, 2013.

27. Matsuura S, Shinmura K, Kamo T, Igarashi H, Maruyama K, Tajima M, Ogawa $\mathrm{H}$, Tanahashi M, Niwa H, Funai K, et al: CD74-ROS1 fusion transcripts in resected non-small cell lung carcinoma. Oncol Rep 30: 1675-1680, 2013.

28. Bifulco C, McDaniel K, Leng L and Bucala R: Tumor growth-promoting properties of macrophage migration inhibitory factor. Curr Pharm Des 14: 3790-3801, 2008.

29. Hadler-Olsen E, Winberg JO and Uhlin-Hansen L: Matrix metalloproteinases in cancer: Their value as diagnostic and prognostic markers and therapeutic targets. Tumour Biol 34: 2041-2051, 2013.

30. Khoufache K, Bazin S, Girard K, Guillemette J, Roy MC, Verreault JP, Al-Abed Y, Foster W and Akoum A: Macrophage migration inhibitory factor antagonist blocks the development of endometriosis in vivo. PLoS One 7: e37264, 2012.
31. Giannice R, Erreni M, Allavena P, Buscaglia M and Tozzi R: Chemokines mRNA expression in relation to the Macrophage migration inhibitory factor (MIF) mRNA and vascular endothelial growth factor (VEGF) mRNA expression in the microenvironment of endometrial cancer tissue and normal endometrium: A pilot study. Cytokine 64: 509-515, 2013.

32. Cao WG, Morin M, Sengers V, Metz C, Roger T, Maheux R and Akoum A: Tumour necrosis factor-alpha up-regulates macrophage migration inhibitory factor expression in endometrial stromal cells via the nuclear transcription factor NF-kappaB. Hum Reprod 21: 421-428, 2006.

33. Stein R, Mattes MJ, Cardillo TM, Hansen HJ, Chang $\mathrm{CH}$, Burton J, Govindan S and Goldenberg DM: CD74: A new candidate target for the immunotherapy of B-cell neoplasms. Clin Cancer Res 13: S5556-S5563, 2007.

34. Berkova Z, Tao RH and Samaniego F: Milatuzumab-a promising new immunotherapeutic agent. Expert Opin Investig Drugs 19: 141-149, 2010.

35. Stein R, Smith MR, Chen S, Zalath M and Goldenberg DM: Combining milatuzumab with bortezomib, doxorubicin, or dexamethasone improves responses in multiple myeloma cell lines. Clin Cancer Res 15: 2808-2817, 2009.

(i) (9) This work is licensed under a Creative Commons Attribution-NonCommercial-NoDerivatives 4.0 International (CC BY-NC-ND 4.0) License. 